\title{
analytical chemistry
}

Subscriber access provided by University of Newcastle, Australia

\section{Article}

\section{Fully Automatic In-Syringe Magnetic Stirring-Assisted Dispersive Liquid-Liquid Microextraction hyphenated to High Temperature Torch Integrated Sample Introduction System-Inductively Coupled Plasma Spectrometer with Direct Analysis of the Organic phase}

Raquel Sanchez, Burkhard Horstkotte, Katerina Fikarova, Hana Sklená\#ová, Salvador Maestre, Manuel Miró, and José Luis Todoli

Anal. Chem., Just Accepted Manuscript • DOI: 10.1021/acs.analchem.7b00400 • Publication Date (Web): 23 Feb 2017

Downloaded from http://pubs.acs.org on February 26, 2017

\section{Just Accepted}

"Just Accepted" manuscripts have been peer-reviewed and accepted for publication. They are posted online prior to technical editing, formatting for publication and author proofing. The American Chemical Society provides "Just Accepted" as a free service to the research community to expedite the dissemination of scientific material as soon as possible after acceptance. "Just Accepted" manuscripts appear in full in PDF format accompanied by an HTML abstract. "Just Accepted" manuscripts have been fully peer reviewed, but should not be considered the official version of record. They are accessible to all readers and citable by the Digital Object Identifier (DOI®). "Just Accepted" is an optional service offered to authors. Therefore, the "Just Accepted" Web site may not include all articles that will be published in the journal. After a manuscript is technically edited and formatted, it will be removed from the "Just Accepted" Web site and published as an ASAP article. Note that technical editing may introduce minor changes to the manuscript text and/or graphics which could affect content, and all legal disclaimers and ethical guidelines that apply to the journal pertain. ACS cannot be held responsible for errors or consequences arising from the use of information contained in these "Just Accepted" manuscripts. 
1 Fully Automatic In-Syringe Magnetic Stirring-Assisted Dispersive Liquid-Liquid

2 Microextraction hyphenated to High Temperature Torch Integrated Sample Introduction System-Inductively Coupled Plasma Spectrometer with Direct Injection of the Organic Phase

5

6 Raquel Sánchez, ${ }^{1}$ Burkhard Horstkotte, ${ }^{2,3}$ Kateřina Fikarová, ${ }^{2}$ Hana Sklenářová, ${ }^{2}$ 7 Salvador Maestre, ${ }^{1}$ Manuel Miró, ${ }^{2,3^{*}}$ Jose-Luis Todolí ${ }^{1 *}$

8

$9{ }^{1}$ University of Alicante, Department of Analytical Chemistry, Nutrition and Food 10 Sciences, P.O. Box 99, 03080, Alicante, Spain

$11 *$ Corresponding author. E-mail: jose.todoli@ua.es

12

$13{ }^{2}$ Charles University, Department of Analytical Chemistry, Faculty of Pharmacy, 14 Heyrovského 1203, 50005 Hradec Králové, Czech Republic

15

$13^{3}$ FI-TRACE group, University of the Balearic Islands, Department of Chemistry, 17 Carreterra de Valldemossa km 7.5, 07122 Palma de Mallorca, Spain

$18 *$ Corresponding author. E-mail: manuel.miro@uib.es 


\begin{abstract}
21 Abstract
22 A proof of concept study involving the on-line coupling of automatic dispersive liquid-liquid 23 microextraction (DLLME) to ICP OES with direct introduction and analysis of the organic 24 extract is herein reported for the first time. The flow-based analyzer features a Lab-In-Syringe 25 (LIS) setup with an integrated stirring system, a Meinhard ${ }^{\circledR}$ nebulizer in combination with a 26 heated single-pass spray chamber, and a rotary injection valve, used as on-line interface 27 between the microextraction system and the detection instrument. Air segmented flow was used 28 for delivery of a microliter fraction of the non-water miscible extraction solvent, $12 \mu \mathrm{L}$ of 29 xylene, to the nebulizer. All sample preparative steps including magnetic stirring assisted 30 DLLME were carried out inside the syringe void volume as a size-adaptable yet sealed mixing 31 and extraction chamber. Determination of trace level concentrations of cadmium, copper, lead, 32 and silver as model analytes has been demonstrated by microextraction as 33 diethyldithiophosphate (DDTP) complexes. The automatic LIS-DLLME method features 34 quantitative metal extraction, even in troublesome sample matrices, such as seawater, salt, and 35 fruit juices, with relative recoveries within the range of $94-103 \%, 93-100 \%$ and $92-99 \%$, 36 respectively. Furthermore, no statistically significant differences at the 0.05 significance level 37 were found between concentration values experimentally obtained and the certified values of 38 two serum standard reference materials.
\end{abstract}


47 Inductively coupled plasma (ICP)-based techniques are deemed the most universal atomic 48 spectrometric techniques for metal assays as they enable detection of practically all metals and 49 metalloids of the periodic table with excellent sensitivity, reproducibility and sample 50 throughput. Besides, continuous improvements of instrumentation and software make ICP51 based techniques user-friendly for routine analysis. However, limitations of instrumental 52 robustness and background interferences in the analysis of high salt content solutions or samples 53 with elevated organic load might jeopardize the reliability of the analytical method. In fact, the 54 occurrence of this kind of matrices might deteriorate the nebulization efficiency, plasma 55 electron density, and even lead to plasma torch shutdown. The sensitivity of ICP OES and ICP56 MS based methods does not in some instances suffice for the detection of elements at trace 57 level concentrations, as might be the case in environmental surveillance studies or health 58 risk/exposure assessment. Several approaches have been developed to overcome or minimize 59 these drawbacks, including sorbent-based analyte preconcentration, ${ }^{1-3}$ the addition of oxygen to 60 avoid carbon deposition, or the elimination of the sample matrix by electrothermal sample 61 vaporization prior to sample injection into the plasma. ${ }^{4,5}$

62 With regard to sample handling strategies, liquid-liquid extraction (LLE) of hydrophobic metal 63 or oxyanion complexes has proven to be a powerful pre-concentration and clean-up approach 64 for trace metal analysis by graphite furnace (GFAAS) and flame atomic adsorption 65 spectrometry. ${ }^{6,7}$ In contrast, measurements by ICP-based techniques require generally in-line 66 desolvation, solvent emulsification, or solvent dilution to yield steady nebulization conditions. ${ }^{4,5}$

67 Few papers report on LLE with back-extraction of the target species into an aqueous phase as a 68 front end to ICP detection..$^{8-11}$ This approach combines the advantages of LLE including salt 69 removal and avoiding typical problems of on-line SPE (backpressure, filter blockage, etc.) along 70 with eluate compatibility with the detector. However, both the operational time and, if 71 automated, the instrumental complexity and effort, e.g. to yield reproducible solvent 72 introduction and reliable phase separation, refrained this LLE mode from further 73 development. ${ }^{1,12,13}$ 
74 As an alternative to matrix elimination, the use of a high efficiency micronebulizer in 75 combination with a heated spray chamber, termed high temperature torch integrated sample 76 introduction system (h-TISIS), has been reported for reliable ICP- assays of complex 77 samples. ${ }^{14,15}$ With the injection of a mere few microliters of sample, matrix effects have showed 78 to become insignificant as the temperature of the spray chamber is set at $350^{\circ} \mathrm{C}$ for fuels and 79 diverse acid digested environmental samples. ${ }^{14,15}$ Moreover, direct analysis of hydrocarbon 80 samples has also proven to be feasible. ${ }^{14}$ Readers are referred to a series of reviews describing 81 instrumental aspects and successful applications of this approach for metal/metalloid 82 determination in organic matrices. ${ }^{4,5}$

83 This work was sparked by the consideration that such versatile sample introduction system 84 could be hyphenated to automatic liquid-liquid microextraction for expedient analysis of 85 organic extracts. In this context, the Lab-In-Syringe (LIS) concept ${ }^{16,17}$ has gained considerable 86 attention as a sample handling tool for straightforward and versatile batch-wise automation of 87 liquid-phase based approaches. Taken as a sequel of the second generation of flow analysis, also 88 called sequential injection analysis, ${ }^{18,19}$ LIS is featured by carrying out the entire procedure in 89 the void volume of the barrel of a gas-tight automated syringe pump operating as an enclosed 90 mixing chamber. Of special impact is the integration of a magnetic stirring bar into the syringe 91 for homogenous sample/reagent mixture and solvent dispersion. ${ }^{20,21}$

92 While there has been significant work harnessing flow-based approaches (mostly flow injection 93 and sequential injection) for automated liquid-liquid extraction of metal species, ${ }^{6,7,22-25}$ with 94 potential implementation in microfluidic devices, ${ }^{24,26,27}$ prior to on-line atomic spectrometric 95 detection, reviewed elsewhere, ${ }^{3,28,30}$ just few papers report on employing LIS, whose versatility 96 has not been fully explored yet. LIS for metal assays has been merely coupled to atomic 97 absorption spectrometric measurements, namely, mercury microextraction and cold vapor 98 atomic absorption spectroscopy $(\mathrm{AAS})^{31,32}$ and more recently to non-dispersive liquid phase 99 extraction of silver followed by GFAAS, ${ }^{33}$ yet studies concerning on-line dispersive liquid- 
100 liquid microextraction (DLLME) as a front-end microextraction approach to multi-elemental

101 ICP OES/MS are still missing.

102 In this paper, in-syringe DLLME is explored for the first time as a "front-end" versatile 103 microextraction platform for ICP-based detection. Diethyldithiophosphate (DDTP) is used as a 104 selective chelating reagent on the basis of its ability of complexing metal species at the usual 105 acidic $\mathrm{pH}$ values for sample conservation ${ }^{34}$ as opposed to its carbamate counterparts, i.e. no 106 additional buffering of sample is needed, which, in turn, make the analytical method 107 straightforward (with no need of $\mathrm{pH}$ optimization) and less prone to blank contamination. As a

\section{Material and methods}

\section{Chemicals and samples}

Ultrapure water was supplied by a three-step ion-exchange system Milli-Q, fed by reverse osmosis, Elix 3, both from Millipore (El Paso, TX, USA). Isopropanol and xylene (Panreac Química S.A., Barcelona, Spain) were employed for the cleaning of the syringe barrel and flow system prior to each extraction and as extraction solvent, respectively. Diethyldithiophosphate ammonium salt (DDTP, $95 \%$ ) was obtained from Sigma Aldrich (Saint Quentin Fallavier, France) and used as a chelating reagent, prepared in aqueous medium. $65 \% \mathrm{HNO}_{3}$ (Suprapur®, Merck KGaA, Darmstadt, Germany) was used to prepare washing solutions and acidify the 
127 standards and samples. An ICP multielement standard solution (Merck IV, Merck KGaA,

128 Darmstadt, Germany) containing $1000 \mathrm{mg}$ element per litre was used to prepare the standards

129 by serial dilutions. Stock and standard solutions were prepared in $2 \%(\mathrm{v} / \mathrm{v}) \mathrm{HNO}_{3}$. Organic

130 multielement standards were prepared by dissolving a certified material (Conostan ${ }^{\circledR} \mathrm{S}-21$,

131 Conoco Specialty Products, Inc., Ponca City, Oklahoma, USA) in xylene. In order to evaluate

132 the reliability of the automatic system for handling complex matrices, a variety of real samples

133 were analyzed: seawater, salt, salt without sodium, grape juice and apple juice. Salt and juice

134 samples were bought in a local supermarket. Coastal seawater was collected in Alicante using

135 pre-cleaned polyethylene flasks. The sample was taken at an approximately $50 \mathrm{~cm}$ depth and

136 stored at $4^{\circ} \mathrm{C}$ in the laboratory. Salt samples were prepared by dissolving $3.5 \mathrm{~g}$ of salt in $10 \mathrm{~mL}$

137 of Milli-Q water. All samples were filtered using $0.45 \mu \mathrm{m}$ nylon syringe filters (Filter-Lab ${ }^{\circledR}$,

138 Filtros Anoia, Barcelona, Spain). Two certified lyophilized control serum samples (ClinChek ${ }^{\circledR}$

139 Controls, Recipe ${ }^{\circledR}$, Munich, Germany) were used as quality control (QC) materials for

140 evaluation of the trueness of the analytical method. Serum samples were reconstituted in $3.0 \mathrm{~mL}$

141 of ultrapure water with gentle mixing until complete dissolution of the lyophilised material.

142

143 Flow setup for automated DLLME

144 The system configuration for lab-in-syringe dispersive liquid-liquid microextraction (LIS-

145 DLLME)-ICP OES assays is illustrated in Fig. 1 and a close up is presented in Fig S1. In all 146 experiments, a MicroSIA device from FIAlab Instruments Inc. (Seattle, WA) was used to

147 assemble the flow manifold. It integrates a $30 \mathrm{~mm}$ Stroke OEM low pressure Syringe Pump (SP,

148 Cavro XCalibur) and an 8 port selection valve (SV, Vici Valvo) furnished with a PTFE rotor.

149 The MicroSIA system contains two auxiliary supply ports of 5 and $24 \mathrm{~V}$ herein utilized for 150 stirring activation and ICP triggering. The SP is furnished with a rotary head valve (HV) with 151 three selectable ports (IN, OUT, and TOP) for tubing connections. A $5 \mathrm{~mL}$-glass syringe (30 $152 \mathrm{~mm}$ lift, $1.45 \mathrm{~mm}$ id, Tecan) was used for performing all solution handling including the 153 DLLME procedure inside. A commercial PTFE covered magnetic stirring bar of $14 \mathrm{~mm}$ size 
154 (4.5 mm diameter) was placed in the syringe barrel. To diminish the resulting dead volume at 155 syringe emptying, the stirrer was flattened by sand papering to $3.5 \mathrm{~mm}$ height and made to 156 length in order to fit snugly into the syringe. The stirrer was forced to spin at approximately 800

157 rpm by generating a rotating magnetic field outside the syringe (see Fig. 1 and Fig. S1). To this end, a pile of seven neodymium magnets (each $3 \mathrm{~mm} \times 5 \mathrm{~mm} \varnothing$ ) was hot-glued on top of a commercial cooling ventilator (12 VDC supply) serving as a cost-effective brushless motor (wings and protection removed). The motor was connected to the syringe piston bar so that the magnets were leveled with the stirring bar inside the syringe at any time. The motor was powered by the $5 \mathrm{~V}$ supply port of the MicroSIA and activated (generating a rotating magnetic field) by software control. By careful adjustment of this arrangement, stirring velocities exceeding $800 \mathrm{rpm}$ were proven applicable

Lateral ports 2-6 of the SV (see Fig. 1) were connected to $2 \%$ (v/v) $\mathrm{HNO}_{3}$ (2), isopropanol (3) and $15 \%(\mathrm{v} / \mathrm{v}) \mathrm{HNO}_{3}$ (8) for syringe chamber cleaning; extraction solvent (4), sample (5), and complexing reagent (6). Using a very short tube of PEEK piercing a wider silicone tube for drainage, port 1 allowed both syringe content discharge to waste during cleaning but also aspiration of air (see Fig. 1). Air inside the syringe enabled vortex formation by stirring, thus promoting solvent dispersion.

Port IN on the syringe HV was connected to the central port of the SV via a $15 \mathrm{~cm}$ long holding coil (HC, PTFE tube, $1.0 \mathrm{~mm}$ i.d.). Port OUT was used to empty the syringe to waste without passing the HC. The TOP position was connected via a $20 \mathrm{~cm}$ transfer line $(0.5 \mathrm{~mm}$ i.d.) to a low pressure (PEEK stator and rotor) six-port injection valve (IV) from Vici-Valco (Schenkon, Switzerland), used as interface between the LIS-based microextraction system and the ICP OES. A PEEK capillary of $8 \mathrm{~cm}(0.25 \mathrm{~mm}$ i.d. $)$ was used as injection loop, the total injection volume including the valve rotor channel was estimated as $12 \mu \mathrm{L}$.

Instrumental control of the extraction system was done via USB using the open-source software Cocosoft, version 4.3 (FI-TRACE, University of the Balearic Islands). ${ }^{37}$ The software is written in Python programming language and enables the use of variables, loops, routines, and 
181 conditionals, and communication via serial interface. Triggering of ICP OES activation and data 182 registration was done by relay contact using the $24 \mathrm{~V}$ supply port of the MicroSIA instrument.

183

184

ICP OES measurements

185

An Optima 4300 DV Perkin-Elmer ICP OES spectrometer (Uberlingen, Germany) was used as detection instrument and the emission intensity signals were axially taken. The system was equipped with a $40.68 \mathrm{MHz}$ free-running generator and a polychromator with an echelle grating. Table 1 summarizes the operational instrumental conditions.

A glass concentric nebulizer (TR-50-C3, Meinhard ${ }^{\circledR}$, Golden, CA) was fitted to a $12 \mathrm{~cm}^{3}$ glass single pass spray chamber (h-TISIS). ${ }^{38}$ The h-TISIS was jacketed with a copper coil connected to a power supply so as to heating the chamber at will. Hereto, the coil temperature was programmed by means of a thermocouple attached to its surface (Desin Instruments, Barcelona, Spain). ${ }^{14}$

194 The solutions were delivered to the nebulizer by a peristaltic pump (Gilson Minipuls3 Model 195 M312, Villiers-le-Bel, France) and a 0.19-mm i.d. PVC-based material with plasticizer (Tygon ${ }^{\circledR}$ 196 R-3607, Ismatec, S.A.) tubing was employed.

197 An air-segmented flow injection methodology was selected to deliver sample volumes at the 5$19815 \mu \mathrm{L}$ level to the instrument. Air was continuously aspirated by means of a peristaltic pump. At 199 a given time and precisely controlled by software, a sample plug was driven to the nebulizer 200 using a carrier stream of air to avoid sample dispersion. Images of the injection of the analyte201 containing organic phase into the ICP torch are compiled in Fig S2. With this system, oxygen 202 was not needed to minimize background interferences in troublesome samples because of two 203 facts: (i) the injected sample volume was a mere of a few microliters; and, (ii) the oxygen in the 204 air stream continuously aspirated could boost the total carbon combustion. Therefore, negligible 205 soot deposits were found throughout the present work. 
208

209

210

211

212

213

214

215

216

217

218

219

220

221

222

223

224

225

226

227

228

229

230

231

232

233

234

\section{Analytical protocol}

The analytical workflows are given as supplementary materials (Tables S1 and S2). The DLLME protocol was started by cleaning the syringe with (1) isopropanol to remove any residues of the extraction solvent from the previous extraction, (2) $15 \%(\mathrm{v} / \mathrm{v}) \mathrm{HNO}_{3}$ and two times with $2 \%(\mathrm{v} / \mathrm{v}) \mathrm{HNO}_{3}$ to keep the syringe free from metal traces, and (3) with the corresponding sample solution, that is, $2 \%(\mathrm{v} / \mathrm{v}) \mathrm{HNO}_{3}$ for blank measurements or the sample solution itself from position 5 of the SV.

The in-syringe DLLME protocol is performed as follows: $250 \mu \mathrm{L}$ of air (to promote vortex formation with the consequent solvent dispersion), $270 \mu \mathrm{L}$ of xylene, $3600 \mu \mathrm{L}$ of sample, a 20 $\mu \mathrm{L}$ air plug (to avoid contact between sample and chelating reagent in the $\mathrm{HC}$ ), $250 \mu \mathrm{L}$ of reagent solution, and a final volume of $180 \mu \mathrm{L}$ air to empty the overall $\mathrm{HC}$ content into the syringe barrel were sequentially aspirated. Immediately before the aspiration of the extraction solvent, stirring at $800 \mathrm{rpm}$ was activated. After an extraction time of $120 \mathrm{~s}$, the stirring was deactivated for phase separation for $30 \mathrm{~s}$, which allowed the xylene droplets to float and to coalesce. Eight repeated activations of the stirrer for a minimum time $(<1 \mathrm{~s}$, not achieving the final stirring rate) were done to remove any xylene residues, which were stuck on the stirring bar.

In the final step, the organic phase was pushed at $80 \mu \mathrm{L} \mathrm{s}^{-1}$ towards the injection valve first to clean the transfer line and push out any residues from the previous injection to waste. Then, aliquots of the solvent $(12 \mu \mathrm{L})$ were injected repeatedly into ICP OES by IV activation into the air flow carrying the injected volume to the h-TISIS at a delivery flow rate of $50 \mu \mathrm{L} \mathrm{min}{ }^{-1}$. Every organic extract was injected three times for assessing the repeatability of the ICP readouts. Finally, the aqueous syringe content was emptied to waste with the HV in position OUT. 


\section{Results and Discussion}

236

237

238

239

240

241

242

243

244

245

246

247

248

249

250

251

252

253

254

255

256

257

258

259

260

\section{Investigation of the h-TISIS-ICP OES operational conditions}

Parameters related to the nebulization and ICP OES measurements including the injection volume of the organic phase, the nebulizer gas flow rate and the spray chamber temperature were evaluated. For injection volumes of xylene larger $>12 \mu \mathrm{L}$, the plasma was unstable and tended to shut down. The nebulizer gas flow rate was also optimized. The evaluated values were in the range of $0.15-0.40 \mathrm{~L} \mathrm{~min}{ }^{-1}$. It was verified that the optimum nebulizer gas flow rate in terms of sensitivity was $0.26 \mathrm{~L} \mathrm{~min}^{-1}$. Higher flow rates might not ensure the quantitative evaporation of the solvent in the aerosol phase within the spray chamber because of the short residence times but lower flow rates might lead to excessively big aerosol droplets.

The effect of the evaporation chamber temperature on the analytical performance was also investigated. ICP OES signal intensities for $\mathrm{Ag}, \mathrm{Cd}, \mathrm{Cu}$ and $\mathrm{Pb}$ were thus recorded at h-TISIS temperatures ranging from 150 to $400{ }^{\circ} \mathrm{C}$. The h-TISIS spray chamber working at temperatures $>300^{\circ} \mathrm{C}$ provided 8,7 and 12 fold-peak height improvements with respect to those at room temperature for $\mathrm{Ag}, \mathrm{Cd}, \mathrm{Cu}$ and $\mathrm{Pb}$, respectively (see Fig. 2). This was due to the enhancement of the aerosol solvent evaporation inside the chamber and, hence, of the analyte mass delivered to the plasma. The working temperature was set to $350^{\circ} \mathrm{C}$ because, under these circumstances, non-spectral interferences by the solvent itself were practically neglegible. ${ }^{14,15}$

The signal obtained for organic standards with h-TISIS working at the optimum experimental conditions was compared with a conventional introduction system (i.e., cyclonic spray chamber operating at room temperature). The nebulizer gas flow rate employed for the conventional system was $0.4 \mathrm{~L} \mathrm{~min}^{-1}$. Table 2 shows that h-TISIS readouts were up to 13 fold improved as compared to those of the cyclonic spray chamber. Limits of detection (LODs) were determined according to the $3 s_{b}$ criterion, where $s_{b}$ was the standard deviation of ten consecutive blank measurements. As expected from the sensitivity data, the highest LODs (Table 2) were obtained for the conventional sample introduction system. It is however important to note that the 
discrepancies observed across the trends in LODs and the analytical readouts are attributed to the dependence of the spray chamber design upon the standard deviation of the background.

Our experimental setup features significant advances as compared to previous works in the field of LIS. ${ }^{20,21}$ For example, the induction of solvent dispersion by stirring bar rotation did not require any additional "driving device" to generate a rotating magnetic field as reported previously. ${ }^{20,21}$ As the syringe pump was placed here in common up-right orientation, the magnetic stirring bar had to move with the piston so that the motor was fixed to the piston bar to assure steady leveling of both motor and stirrer. To reach the required rotation rate of $800 \mathrm{rpm}$ for solvent dispersion, the stirring bar had to turn smoothly inside the syringe. A $15 \times 4 \mathrm{~mm}$ stirring bar was thus sandpapered to a $14 \mathrm{~mm}$ length (syringe inner diameter was $14.5 \mathrm{~mm}$ ). Smaller stirring bars (e.g. $10 \mathrm{~mm} \times 2 \mathrm{~mm}$ ), potentially offering a lower dead volume, were not able to keep up with the required rotation rate but dangle inside the syringe. Due to the inertia of the liquid, the stirring bar is slowed down at the onset of stirring. Thus, a purpose-made control circuit was used for a slow turn-on of the inducing motor. ${ }^{20}$ The motor then reached its final speed after approximately $5 \mathrm{~s}$, which enabled synchronized rotation of the stirring bar.

Regarding the analytical protocol for in-syringe DLLME, the following two operational sequences for in-line sequential aspiration of solutions to the syringe were tested: 1: Air, extraction solvent, sample, air, DDTP reagent and air; and, 2: Air, sample, air, DDTP reagent, extraction solvent and air. The segmentation between the sample and the DDTP reagent was done to prevent complex formation already inside the holding coil and the potential sorption of the chelate onto the hydrophobic walls of the flow manifold, which would in turn jeopardize the precision and the analyte recovery and lead to carry-over effects. Air was further found to favor vortex formation with the consequent dispersion of the extraction solvent into tiny droplets. It was demonstrated that the first aspiration sequence was superior in terms of peak height (1.4-1.5 times higher signal) and thus was kept further on. Because the extraction solvent was the first 
288 solution introduced into the syringe, smaller droplets were formed, thus enhancing the surface

289 area with the subsequent improvement of the extraction efficiency.

290 One disadvantage of the LIS-based extraction system herein proposed is the potential cross-over 291 contamination because of the syringe void volume caused by the stirring bar along with the 292 possibility of sorption of organic phase droplets onto the PTFE bar. Generally, the rinsing of the 293 syringe after extraction is done in three steps; a first cleaning step with isopropanol, to remove 294 organic solvent remnants; a second step with a concentration of nitric acid ranging from 2-15\% $295(\mathrm{v} / \mathrm{v})$ to remove metal leftovers and, finally, with the sample, in order to rinse the system with 296 the sample matrix itself. However, the hydrophobic analyte complexes can further be retained in 297 the tubing and injection valve, potentially leading to carry-over effects. To evaluate the 298 effectiveness of several cleaning protocols (see Table S3), the concentrations of metals in three 299 consecutive blank samples analyzed after a standard of $100 \mu \mathrm{g} \mathrm{L}^{-1}$ of $\mathrm{Ag}, \mathrm{Cd}, \mathrm{Cu}$, and $\mathrm{Pb}$ were 300 determined. Figure S3 shows the percentage of the Ag blank signals in consecutive injections 301 with respect to that obtained at the $100 \mu \mathrm{g} \mathrm{L} \mathrm{L}^{-1}$ level. The rinsing protocol capitalizing upon $15 \%$ $302(\mathrm{v} / \mathrm{v}) \mathrm{HNO}_{3}$ provided the best performance because signals for the first extraction of the blank 303 corresponded to only $5 \%$ of the signal obtained for the $100 \mu \mathrm{g} \mathrm{L}^{-1}$ standard. Similar results were 304 found for $\mathrm{Cd}, \mathrm{Cu}$ and $\mathrm{Pb}$. In the remainder of washing protocols using 2-10\% (v/v) $\mathrm{HNO}_{3}$, the 305 first blank signal amounted to as much as ca $20-95 \%$ of the initial Ag signal.

The volume of the extraction solvent in the automatic LIS procedure is particularly important inasmuch as large volumes facilitate quantitative extraction efficiency while microvolumes 311 (usually a few microliters) are preferable with respect to the improvement of preconcentration 312 factors. Evaluation of the volume of xylene as extraction solvent was performed by comparison 313 of the analytical readouts obtained for volumes in the range of 220 to $320 \mu \mathrm{L}$ at the $100 \mu \mathrm{g} \mathrm{L}^{-1}$ 
314 level. Larger solvent volumes were considered unacceptable for analyte enrichment while 315 smaller volumes of solvent were unlikely to be applicable herein as the system's reliability is 316 based on the premise that the solvent droplets coalesce to one phase so that introduction of 317 droplets of the aqueous phase into the h-TISIS-ICP OES is circumvented. The ICP OES signals 318 were normalized with respect to the maximum peak height (obtained with $270 \mu \mathrm{L}$ ). Figure S4 319 indicates that the normalized readouts increased with the volume of extraction solvent up to 270 $\mu \mathrm{L}$, with repeatabilities in all instances better than $3 \%$. Similar trends were found for peak area; hence, the analytical signal was taken as peak height throughout. Note that similar behavior was found for all the elements, therefore, $\mathrm{Ag}$ and $\mathrm{Cd}$ were selected as model analytes for further studies.

In DLLME, the higher the interfacial area between immiscible phases is the shorter the extraction time for attaining comparable extraction efficiencies. For a fixed stirring rate (viz., $800 \mathrm{rpm}$ ), the effect of the stirring time was evaluated. The minimum extraction time to achieve pseudo-equilibrium conditions was estimated at the onset of the curvature of the regression line of the peak height against extraction time for which the analytical readouts approach to steadystate conditions. The pseudo-equilibrium conditions were reached at $60-65 \mathrm{~s}$ for all the elements under the experimental conditions indicated above. Moreover, it was observed that almost $100 \%$

331 (in absolute mass) of the analytes were extracted in the organic phase for stirring times of 100$120 \mathrm{~s}$. For stirring times $>100 \mathrm{~s}$ the influence of the extraction time was virtually negligible as the peak height remained practically unaltered. However, the intra-day precision improved with the extraction time, reaching RSD values lower than $5 \%$ at $120 \mathrm{~s}$. An extraction time of $120 \mathrm{~s}$ was therefore chosen for the remaining work. The concentration of the extraction agent was also evaluated. Figure S5 indicates that peak heights increased with DDTP concentration up to 50 $\mathrm{mmol} \mathrm{L}^{-1}$, which was selected for the remainder of the experiments. 
340 The effect of the acid nature and counter ions on the extraction efficiency of target metals was 341 evaluated. Hence, a cohort of six standards was prepared with the same metal concentration but 342 with increasing concentrations of strong acids $\left(\mathrm{HCl}\right.$ or $\left.\mathrm{HNO}_{3}\right)$ to evaluate the potential salting343 out effects and metal complexation. The matrix composition was: $0.21,0.51$ or $1.03 \mathrm{~mol} \mathrm{~L}^{-1}$ in $344 \mathrm{HNO}_{3}$ or $\mathrm{HCl}$. According to previous researchers, ${ }^{21}$ the effect of the two counter anions as 345 interfering species for DDTP extraction was not statistically significant (Fig. S6). With respect 346 to the acidity of the sample matrix, a loss of signal intensity was observed at the concentration 347 level of $1.03 \mathrm{~mol} \mathrm{~L}^{-1}$ regardless of the acid nature. For nitric acid, $6 \%$ and $12 \%$ signal losses 348 were observed for $\mathrm{Ag}$ and $\mathrm{Cu}$, respectively. On the other hand, a $7 \%$ loss of peak height was 349 observed in both cases for $1.03 \mathrm{~mol} \mathrm{~L}^{-1} \mathrm{HCl}$.

Analytical method performance

352 Under the selected experimental conditions, a linear correlation of peak height against analyte 353 concentration in aqueous medium subjected to automatic DLLME was observed. The 354 calibration was performed using six concentration levels in aqueous phase from 0.4 up to $11 \mu \mathrm{g}$ $355 \mathrm{~L}^{-1}$ with an injection volume of $12 \mu \mathrm{L}$ of organic phase. Coefficients of determination $\left(\mathrm{R}^{2}\right)$ 356 higher than 0.9991 were obtained for five inter-day calibration curves. As a benchmark of inter357 day precision, relative standard deviations were $5,7,4$, and $8 \%$ for the slopes of the calibration 358 curves of $\mathrm{Ag}, \mathrm{Cd}, \mathrm{Cu}$, and $\mathrm{Pb}$, respectively. Moreover, no outlying measurements ( $>$ three times 359 the standard error of the slope) were found. LODs were calculated according to the $3 s_{b}$ criterion $360(\mathrm{n}=10)$, and in all instances were lower than $0.1 \mu \mathrm{g} \mathrm{L} \mathrm{L}^{-1}$. LOQs were $0.16,0.14,0.14$ and $0.21 \mu \mathrm{g}$ $361 \mathrm{~L}^{-1}$ for $\mathrm{Ag}, \mathrm{Cd}, \mathrm{Cu}$, and $\mathrm{Pb}$, respectively. Repeatability values for six consecutive analysis of a $3622.0 \mu \mathrm{g} \mathrm{L}^{-1}$ aqueous standard were 3.1, 4.0, 2.8 and 3.9 \% for $\mathrm{Ag}, \mathrm{Cd}, \mathrm{Cu}$ and $\mathrm{Pb}$, respectively.

363 An alternative calibration method was also tested. In this case, organic standards $(12 \mu \mathrm{L})$ were 364 introduced directly to the ICP OES following the air-segmented injection methodology 365 described above. Organic standards were prepared using xylene as a diluent of the certified 
reference material Conostan ${ }^{\circledR}$ S-21. Coefficients of determination $\left(R^{2}\right)$ higher than 0.9993 were obtained for five calibration curves within the concentration range spanning from 5-170 $\mu \mathrm{g} / \mathrm{L}$ on 5 subsequent days. The inter-day precision in terms of sensitivity was similar to that of the procedure with aqueous standards followed by DLLME. Notwithstanding the deterioration in sensitivity (see Table 3) as the organic standards in this second external calibration method are not subjected to preconcentration, LOQs were not proportionally increased because of the deterioration of the blank repeatability values for the LIS-DLLE method. Repeatability values for six consecutive analysis of a $25 \mu \mathrm{g} \mathrm{L^{-1 }}$ organic standard were were $2.1,3.4,2.7$ and $4.2 \%$ for $\mathrm{Ag}, \mathrm{Cd}, \mathrm{Cu}$ and $\mathrm{Pb}$, respectively.

The preconcentration factor was obtained as the ratio of the slope of the straight line regression following the automatic LIS extraction procedure to that obtained by direct injection of organic standards into h-TISIS-ICP OES. Table 3 compiles the sensitivities of both calibration curves. The nominal pre-concentration factor was estimated from the ratio of the sample volume (3.60 $\mathrm{mL})$ to that of the organic solvent $(270 \mu \mathrm{L})$, that is, 13.3 . Table 3 shows that the experimentally obtained pre-concentration factors were similar to the nominal value, thus signalling that the extraction efficiency for all the metals was close to $100 \%$.

The entire automatic LIS procedure, including mixing of the sample and reagents, extraction, phase separation, measurement and system cleaning, lasted ca. $375 \mathrm{~s}$, which gives rise to a

Analysis of real samples

With the aim of validating the extraction methodology, five real samples including seawater, salt, salt without sodium, grape juice and apple juice were analyzed by LIS-DLLME. To this end, a given aliquot was spiked with $2.0 \mu \mathrm{g} \mathrm{L}^{-1}$ of a multi-elemental solution in the aqueous 392 phase. Consequently, the analytical concentration in the organic phase after the preconcentration 
393 step was around $25 \mu \mathrm{g} \mathrm{L}^{-1}$. Note that the non-spiked samples were also analyzed. Original metal 394 concentrations are summarized in Table S4.

395 Table 4 (right) lists the relative recoveries for $\mathrm{Ag}, \mathrm{Cd}, \mathrm{Cu}$ and $\mathrm{Pb}$, which were close to $100 \%$ in 396 all the cases. It can therefore be concluded that additive or multiplicative matrix effects for any 397 of the tested samples, even for typically not applicable samples of high salt content, were 398 insignificant. Recovery values were also calculated using a calibration curve obtained by direct 399 injection of the organic standards into the ICP (see Table 4 left). In this case, the concentration 400 of the organic standards was divided by the preconcentration factor and used as X-axis data with 401 the ICP OES readouts as Y-axis for direct analysis of the spike recoveries in the aqueous phase. 402 Experimental results compiled in Table 4 demonstrated that both external calibration methods 403 provide comparable metal recoveries for all the samples with troublesome matrices. It is 404 important to point out that there is no need to subject the aqueous standards to the DLLME 405 procedure to get reliable results as the target metals regardless of the matrix composition were 406 quantitatively extracted in the organic phase.

407 For further QC/QA assessment, two serum reference materials, differentiated by the level of 408 metal concentration, were analyzed by LIS-DLLME. For further QC/QA assessment, two serum 409 certified reference materials (CRM), differentiated by the level of metal concentration, were 410 analyzed by LIS-DLLME. Statistical assessment of experimental data for the CRMs was 411 done by comparison of the difference between the certified and the measured values 412 against the associated expanded uncertainty $\left(U_{\Delta}\right)$ because the number of accepted sets of 413 data is not provided in the CRM report. The absolute difference $\left(\Delta_{m}\right)$ between the mean 414 measured value $\left(c_{m}\right)$ and the mean certified value $\left(c_{C R M}\right)$ is calculated according to 415 equation 1 . The combined uncertainty $\left(u_{\Delta}\right)$ was calculated, based on equation 2 , from 416 the uncertainty of the certified value $\left(u_{C R M}\right)$ and the standard deviation $\left(s_{m}\right)$ of the 417 experimental data. The expanded uncertainty $U_{\Delta}$ for a confidence level of 418 approximately $95 \%$ is obtained by multiplying the combined uncertainty $\left(u_{\Delta}\right)$ by a 
419 coverage factor $(\mathrm{k})$ equal to 2 (Equation 3). To evaluate the method performance, $\Delta_{m}$

420 was compared against $U_{\Delta}$. Because $\Delta_{m}$ is in all cases $<U_{\Delta}$, no statistically significant

421 differences were found at the $95 \%$ level between the values obtained experimentally and

422 the certified concentrations for any of the target elements (see Table 5 and Table S5).

\section{Conclusions}

In this work, a novel approach capitalizing on a portable flow setup has been proposed for the

431 first time for the coupling of automatic in-syringe magnetic stirring-assisted dispersive liquid-

432 liquid microextraction to ICP spectrometry for direct analysis of metal laden organic extracts

433 using an h-TISIS-based total sample consumption system. With this miniaturized sample 434 introduction system, negligible matrix effects were observed in the analysis of carbon435 containing matrixes. Because of the high stability constants of DDTP-metal chelates, back436 extraction to aqueous phase for conventional ICP measurements in the aqueous phase is proven 437 unfeasible. Using a univariate optimization strategy suitable experimental conditions were 438 found for DLLME-h-TISIS-ICP OES detection of trace level concentrations of target elements 439 in troublesome samples with enrichment factors of ca. 13. Limits of detection found for two 440 distinct calibration procedures were: $0.05,0.04,0.04$ and $0.06 \mu \mathrm{g} \mathrm{L}^{-1}$ for $\mathrm{Ag}, \mathrm{Cd}, \mathrm{Cu}$ and $\mathrm{Pb}$ 441 (extraction procedure) and $0.07,0.09,0.06$ and $0.10 \mu \mathrm{g} \mathrm{L}^{-1}$ for $\mathrm{Ag}, \mathrm{Cd}, \mathrm{Cu}$ and $\mathrm{Pb}$ (direct 442 injection of standards) respectively, allowing its successful application to the analysis of 443 certified serum materials and spiked environmental samples and beverages. Efficiencies of 
444 extraction were close to $100 \%$ with repeatabilities usually down to $8 \%$. Therefore, external 445 calibration can be streamlined by direct injection of organic standards into the h-TISIS-ICP 446 detector system with no need to subject them to the extraction procedure. Further work is 447 underway to expand the scope of the hyphenated LIS-DLLME-h-TISIS-ICP system for 448 detection of bioaccessible metals, metalloids and organometallic compounds in complex 449 foodstuff and soil extracts.

450

451 Supplementary Information. Additional experimental data and information includes 452 (i) Images of the flow setup and plasma characteristics, (ii) Readouts of cleaning 453 procedures and operational steps, (iii) Effect of volume of organic phase on the 454 analytical readouts, (iv) Effect of chelating reagent concentration on the analytical 455 readouts, (v) Effect of acid type and concentration on the analytical readouts, (vi) 456 Detailed analytical procedure and cleansing protocol, (vii) Concentration of targeted 457 species in the real samples and (viii) Statistical analysis of experimental data for CRM.

459 Acknowledgements

460 B. Horstkotte acknowledges the financial support by an ERASMUS+ scholarship No XIII / 3/ 461 15-16 and by the Czech Science Foundation (project no. P206/15/10781S). K. Fikarová is 462 thankful for an Erasmus student scholarship and financial support of the Charles University 463 (Project SVV 260 292/2016). M. Miró acknowledges financial support from the Spanish State 464 Research Agency through projects CTM2014-56628-C3-3-R (AEI/FEDER, UE) and 465 CTM2014-61553-EXP (AEI/FEDER, UE). 
1

2

3

4

5

6

7

8

9

10

11

12

13

14

15

16

17

18

19

20

21

22

23

24

25

26

27

28

29

30

31

32

33

34

35

36

37

38

39

40

41

42

43

44

45

46

47

48

49

50

51

52

53

54

55

56

57

58

59

60
467 Table 1. Operating conditions of the ICP OES furnished with h-TISIS for injection of 468 organic samples

\begin{tabular}{lc} 
Variable & Value \\
\hline Injected sample volume $[\mu \mathrm{L}]$ & 12 \\
Nebulizer gas flow, $\mathrm{Q}_{\mathrm{g}}\left[\mathrm{L} \mathrm{min}{ }^{-1}\right]$ & 0.26 \\
Outer gas flow [L min $\left.{ }^{-1}\right]$ & 15 \\
Intermediate gas flow $\left[\mathrm{L} \mathrm{min}{ }^{-1}\right]$ & 1.0 \\
Rf power [kW] & 1.35 \\
Integration time [ms] & 25 \\
Sampling time [s] & 1 \\
Plasma viewing mode] & $\mathrm{Axial}$ \\
Temperature spray chamber $\left[{ }^{\circ} \mathrm{C}\right]$ & $\mathrm{Pb} 220.353$ \\
\hline
\end{tabular}

469

470 
471 Table 2. Peak height and LODs obtained for the h-TISIS compared against those obtained

472 for the conventional system.*

\begin{tabular}{|c|c|c|c|c|c|c|c|c|}
\hline & & TISIS & & Conven & ional s & ystem $^{\Phi}$ & Dol thoight(h-TISIS) & \\
\hline & $\begin{array}{c}\text { Peak } \\
\text { height }\end{array}$ & $\begin{array}{l}\text { RSD } \\
(\%)\end{array}$ & $\begin{array}{c}\text { LOD } \\
\left(\mu \mathrm{g} \mathrm{L}^{-1}\right)\end{array}$ & $\begin{array}{l}\text { Peak } \\
\text { height }\end{array}$ & $\begin{array}{l}\text { RSD } \\
(\%)\end{array}$ & $\begin{array}{c}\text { LOD } \\
\left(\mu \mathrm{g} \mathrm{L}^{-1}\right)\end{array}$ & Peak height ${ }^{(\text {Conventional })}$ & LOD $^{(\mathrm{hTISIS})}$ \\
\hline Ag & $6.1 \times 10^{5}$ & 2.4 & 0.6 & $5.0 \times 10^{4}$ & 11.2 & 2.3 & 12 & 4 \\
\hline Cd & $1.4 \times 10^{4}$ & 7.2 & 0.4 & $1.3 \times 10^{3}$ & 9.5 & 3.6 & 11 & 10 \\
\hline $\mathbf{C u}$ & $8.1 \times 10^{5}$ & 2.7 & 0.5 & $6.1 \times 10^{4}$ & 1.6 & 1.9 & 13 & 4 \\
\hline $\mathbf{P b}$ & $1.4 \times 10^{4}$ & 4.6 & 0.4 & $1.4 \times 10^{3}$ & 10.3 & 2.1 & 10 & 5 \\
\hline
\end{tabular}

473

474

* Metal concentration: $100 \mu \mathrm{g} \mathrm{L}^{-1}$ in xylene. Injected volume: $12 \mu \mathrm{L} . \mathrm{Q}_{\mathrm{g}}$ (h-TISIS): $0.26 \mathrm{~L} \mathrm{~min}{ }^{-1}, \mathrm{Q}_{\mathrm{g}}$ (Conventional system): $0.40 \mathrm{~L} \mathrm{~min}^{-1}$.

$475 \Phi 10$ replicates.

476 
1

2

3

4

5

6

7

8

9

10

11

12

13

14

15

16

17

18

19

20

21

22

23

24

25

26

27

28

29

30

31

32

33

34

35

36

37

38

39

40

41

42

43

44

45

46

47

48

49

50

51

52

53

54

55

56

57

58

59

60

477 Table 3. Slopes of the calibration curves by the automatic LIS-DLLME procedure and the 478 direct injection of organic standards along with the experimental pre-concentration

479 factors

\begin{tabular}{|c|c|c|c|}
\hline & $\begin{array}{c}\text { Slope - Aqueous } \\
\text { standards - LIS-DLLME } \\
\text { procedure }\left(\mathrm{L} \boldsymbol{\mu g}^{-1}\right)\end{array}$ & $\begin{array}{c}\text { Slope - Organic } \\
\text { standards - Direct } \\
\text { injection }\left(\mathrm{L} \mu \mathrm{g}^{-1}\right)\end{array}$ & $\begin{array}{c}\text { Pre-concentration } \\
\text { factor }\end{array}$ \\
\hline Ag & $1.1 \times 10^{5}$ & $8.1 \times 10^{3}$ & 13.6 \\
\hline Cd & $1.7 \times 10^{3}$ & $0.13 \times 10^{3}$ & 13.1 \\
\hline $\mathbf{C u}$ & $7.9 \times 10^{4}$ & $5.9 \times 10^{3}$ & 13.4 \\
\hline $\mathbf{P b}$ & $1.9 \times 10^{3}$ & $0.14 \times 10^{3}$ & 13.5 \\
\hline
\end{tabular}

480

481 
Table 4. Relative recoveries (\%) for complex samples using the LIS-DLME-h-TISIS-ICP OES system

\begin{tabular}{|c|c|c|c|c|c|c|c|c|c|c|c|c|c|c|c|c|}
\hline \multirow{3}{*}{ Samples } & \multicolumn{8}{|c|}{ Standards: Direct injection * } & \multicolumn{8}{|c|}{ Standards: Extraction procedure ${ }^{\#}$} \\
\hline & \multicolumn{2}{|c|}{ Ag } & \multicolumn{2}{|c|}{$\mathbf{C d}$} & \multicolumn{2}{|c|}{$\mathbf{C u}$} & \multicolumn{2}{|c|}{$\mathbf{P b}$} & \multicolumn{2}{|c|}{ Ag } & \multicolumn{2}{|c|}{ Cd } & \multicolumn{2}{|c|}{$\mathbf{C u}$} & \multicolumn{2}{|c|}{$\mathbf{P b}$} \\
\hline & Mean & $\begin{array}{l}\text { RSD } \\
(\%)\end{array}$ & Mean & $\begin{array}{l}\text { RSD } \\
(\%)\end{array}$ & Mean & $\begin{array}{l}\text { RSD } \\
(\%)\end{array}$ & Mean & $\begin{array}{l}\text { RSD } \\
(\%)\end{array}$ & Mean & $\begin{array}{l}\text { RSD } \\
(\%)\end{array}$ & Mean & $\begin{array}{c}\text { RSD } \\
(\%)\end{array}$ & Mean & $\begin{array}{l}\text { RSD } \\
(\%)\end{array}$ & Mean & $\begin{array}{l}\text { RSD } \\
(\%)\end{array}$ \\
\hline Seawater & 94 & 1.4 & 96 & 1.1 & 103 & 0.5 & 95 & 0.6 & 95 & 1.4 & 97 & 1.1 & 103 & 0.5 & 96 & 0.6 \\
\hline Salt $A$ & 98 & 1.1 & 99 & 0.6 & 95 & 0.2 & 94 & 0.3 & 99 & 1.1 & 100 & 0.6 & 97 & 0.2 & 95 & 0.3 \\
\hline $\begin{array}{l}\text { Salt B } \\
\text { (Without Na) }\end{array}$ & 96 & 1.2 & 98 & 1.1 & 96 & 1.1 & 93 & 2.0 & 97 & 1.2 & 100 & 1.1 & 97 & 1.1 & 94 & 2.0 \\
\hline Apple juice & 98 & 0.9 & 95 & 1.1 & 97 & 1.2 & 94 & 1.0 & 99 & 0.9 & 96 & 1.0 & 98 & 1.2 & 96 & 1.0 \\
\hline Grape juice & 97 & 0.3 & 92 & 2.0 & 97 & 1.1 & 97 & 0.7 & 97 & 0.3 & 93 & 2.0 & 98 & 1.1 & 98 & 0.7 \\
\hline
\end{tabular}

* The standards were prepared in xylene and directly injected in triplicate into the h-TISIS-ICP OES without the use of the extraction procedure.

\# The standards were prepared in Ultrapure water, then analyte extraction was performed into xylene (in triplicate) and, finally, a small volume of each extract (in triplicate) was injected into the h-TISIS-ICP OES 
Table 5. Concentrations for the reconstituted certified serum samples as obtained by the automatic LIS-DLLME procedure

\begin{tabular}{|c|c|c|c|c|c|c|c|c|c|c|c|c|}
\hline & \multicolumn{6}{|c|}{ Serum - Level I } & \multicolumn{6}{|c|}{ Serum - Level II $^{\Phi}$} \\
\hline & \multicolumn{2}{|c|}{ Ag } & \multicolumn{2}{|c|}{ Cd } & \multicolumn{2}{|c|}{$\mathrm{Cu}$} & \multicolumn{2}{|c|}{ Ag } & \multicolumn{2}{|c|}{ Cd } & \multicolumn{2}{|c|}{$\mathbf{C u}$} \\
\hline & $\begin{array}{c}\text { Mean } \\
\left(\mu \mathrm{g} \mathrm{L}^{-1}\right)\end{array}$ & $\begin{array}{c}\mathrm{s} \\
\left(\mu \mathrm{g} \mathrm{L}^{-1}\right)\end{array}$ & $\begin{array}{c}\text { Mean } \\
\left(\mu \mathrm{g} \mathrm{L}^{-1}\right)\end{array}$ & $\begin{array}{c}\mathrm{s} \\
\left(\mu \mathrm{g} \mathrm{L}^{-1}\right)\end{array}$ & $\begin{array}{c}\text { Mean } \\
\left(\mu \mathrm{g} \mathrm{L}^{-1}\right)\end{array}$ & $\begin{array}{c}\mathrm{S} \\
\left(\mu \mathrm{g} \mathrm{L}^{-1}\right)\end{array}$ & $\begin{array}{c}\text { Mean } \\
\left(\mu g \mathrm{~L}^{-1}\right)\end{array}$ & $\begin{array}{c}\mathrm{S} \\
\left(\mu \mathrm{g} \mathrm{L}^{-1}\right)\end{array}$ & $\begin{array}{c}\text { Mean } \\
\left(\mu \mathrm{g} \mathrm{L}^{-1}\right)\end{array}$ & $\begin{array}{c}\mathrm{s} \\
\left(\mu \mathrm{g} \mathrm{L}^{-1}\right)\end{array}$ & $\begin{array}{c}\text { Mean } \\
\left(\mu \mathrm{g} \mathrm{L}^{-1}\right)\end{array}$ & $\begin{array}{c}\mathrm{s} \\
\left(\mu \mathrm{g} \mathrm{L}^{-1}\right)\end{array}$ \\
\hline $\begin{array}{l}\text { Extraction } \\
\text { procedure* }\end{array}$ & $9.29^{¥}$ & 0.09 & $2.2^{¥}$ & 0.01 & $0.775^{¥}$ & 0.002 & $47.3^{\Phi}$ & 0.2 & $4.62^{\Phi}$ & 0.01 & $1.23^{\mathrm{\Phi}}$ & 0.01 \\
\hline Direct injection $^{\#}$ & 9.49 & 0.09 & 2.2 & 0.02 & 0.781 & 0.003 & 47.5 & 0.2 & 4.63 & 0.01 & 1.22 & 0.02 \\
\hline Certified value* & 9.85 & 2.00 & 2.28 & 0.47 & 0.801 & 0.122 & 48.0 & 9.8 & 4.54 & 0.93 & 1.34 & 0.20 \\
\hline
\end{tabular}

*The standards were prepared in Ultrapure water, and analyte extraction was performed into xylene (in triplicate). A small volume of the extract (in triplicate) was injected into the h-TISIS-ICP OES.

$¥$ The calibration was performed using seven concentration levels of aqueous standards ranging from 0.3 up to $11 \mu \mathrm{g} \mathrm{L}{ }^{-1}$.

${ }^{\Phi}$ The calibration was performed using eight concentration levels of aqueous standards ranging from 1 up to $15 \mu \mathrm{g} \mathrm{L}{ }^{-1}$. For Ag determination, the sample was $1: 4$ diluted with Ultrapure water.

\# The standards were prepared in xylene and directly injected in triplicate into the h-TISIS-ICP OES without applying the extraction procedure. The calibration was performed using ten concentration levels of organic standards ranging from 0.5 up to $170 \mu \mathrm{g} \mathrm{L}^{-1}$.

* The standard deviation was estimated as the combined standard uncertainty with a coverage factor of 1.96 at the $95 \%$ confidence level. 


\section{Figure captions}

Figure 1. Outline of the automatic and miniaturized LIS-DLLME system. HV - Head valve (of syringe, positions IN, OUT, and TOP), IV - Injection valve, IL - Injection loop, $8 \mathrm{~cm}, 0.25 \mathrm{~mm}$ i.d., $\mathrm{M}$ - DC motor, PP - Peristaltic pump, SP - Syringe pump, SV - Selection valve. Tube dimensions: A $-5 \mathrm{~cm}, 0.8 \mathrm{~mm}$ i.d., B $-15 \mathrm{~cm}, 1.0 \mathrm{~mm}$ i.d., $\mathrm{C}$ - Transfer line $20 \mathrm{~cm}, 0.5 \mathrm{~mm}$ i.d., $\mathrm{E}-20 \mathrm{~cm}, 0.25 \mathrm{~mm}$ i.d. (PEEK), $\mathrm{F}$ - red-orange peristaltic/elastic tube, $40 \mathrm{~cm}, 0.16 \mathrm{~mm}$ i.d., $\mathrm{G}-$ Magnetic stirring bar.

Figure 2. Normalized peak height with respect of that obtained at room temperature for different analytes and h-TISIS temperatures. Metal concentration: $100 \mu \mathrm{g} \mathrm{L}^{-1}$. Injected volume: $12 \mu \mathrm{L}$ xylene. $\mathrm{Q}_{\mathrm{g}}: 0.26 \mathrm{~L} \mathrm{~min}^{-1}$. 


\section{Figure 1}

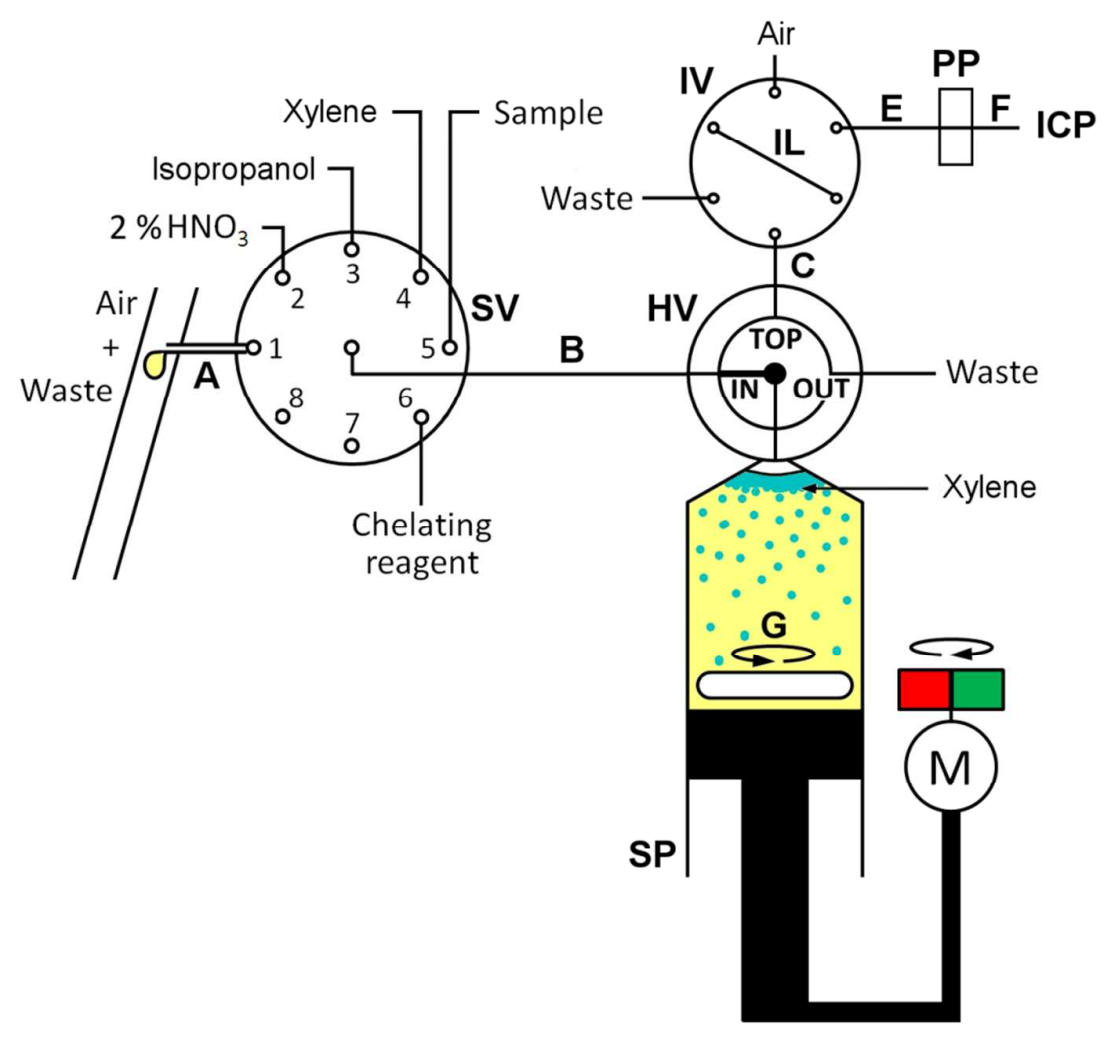

30

31

32

33

34

35

36

37

38

39

40

41

42

43

44

45

46

47

48

49

50

51

52

53

54

55

56

57

58

59

60 
Figure 2

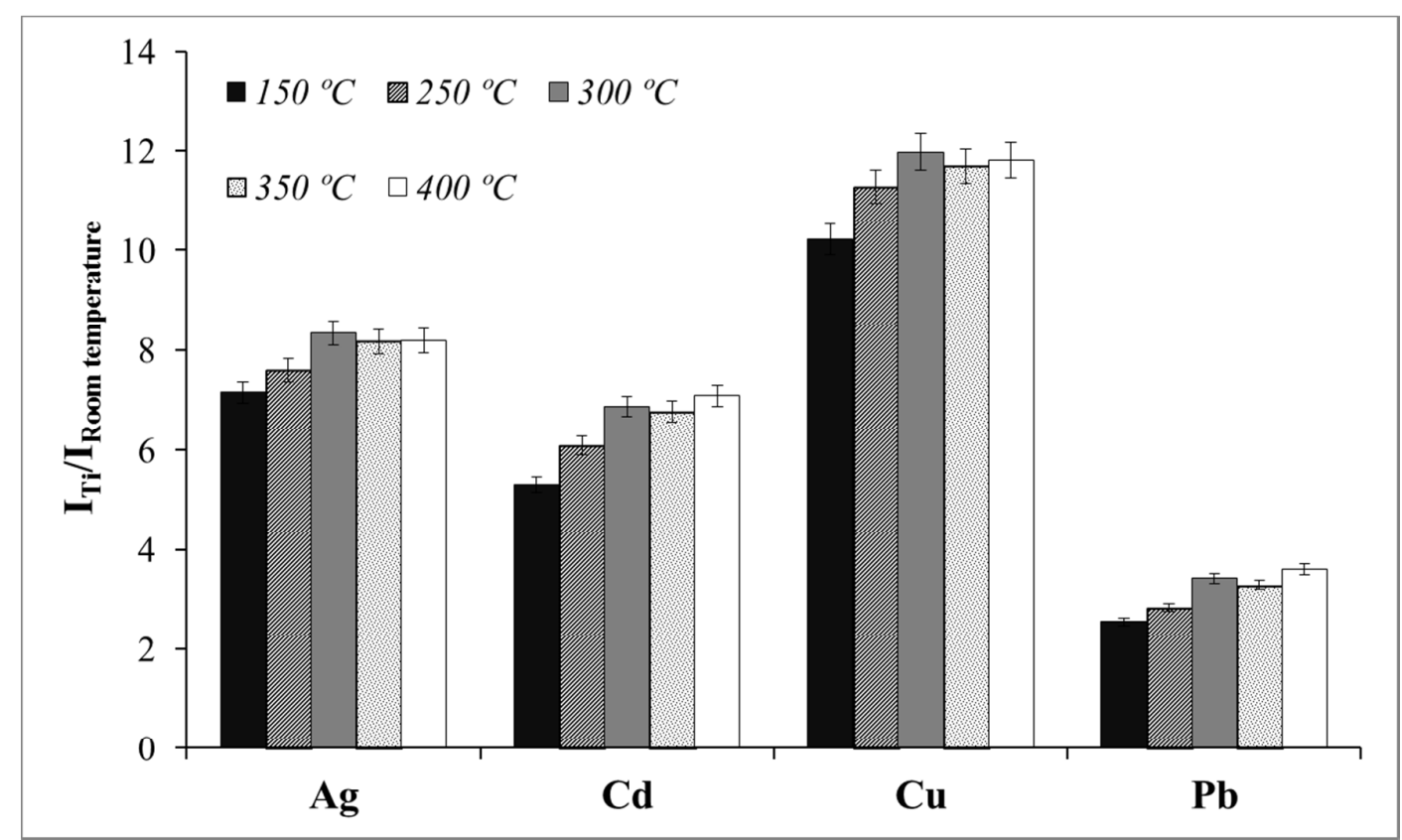

1

2

3

4

5

6

10

11

12

13

14

15

16

17

18

19

20

21

22

23

24

25

26

27

28

29

30

31

32

33

34

35

36

37

38

39

40

41

42

43

44

45

46

47

48

49

50

51

52

53

54

55

56

57

58

59

60 


\section{References}

${ }^{1}$ Wang, J.; Hansen, E.H.;Anal.Chim.Acta, 2002, 456, 283-292.

${ }^{2}$ Hansen, E.H.; J.Environ.Sci.Health A Tox.Hazard.Subst.Environ.Eng.,2005, 40, $1507-$ 1524.

${ }^{3}$ Miró,M.;Hansen,E.H.;Anal.Chim.Acta,2013,782, 1-11.

${ }^{4}$ Leclercq,A.;Nonell,A.;Todolí,J.L.;Bresson,C.;Vio,L.;Vercouter,T.;Chartier,F.;Anal Chim. Acta,2015,885, 33-56.

${ }^{5}$ Leclercq, A.;Nonell, A.;Todolí, J.L.;Bresson,C.;Vio,L.;Vercouter,T.;Chartier,F.; Anal Chim. Acta, 2015, 885, 57-91.

${ }^{6}$ El-Shahawi,M.S.;Al-Saidi,H.M.;TrAC-Trends Anal.Chem.,2013,44, 12-24.

${ }^{7}$ Andruch,V.;Balogh,I.S.;Kocurova,L.; Šandrejová,J.; J. Anal.At.Spectrom.,2013, 28,1932.

${ }^{8}$ Satyanarayanan,M.;Balaram,V.;Rao,T.G.;Dasaram,B.;Ramesh,S.L.;Mathur,R.,Drolia, R.K.; Indian J. Mar. Sci,2007,36, 71-75.

${ }^{9}$ Jia,X.;Han,Y.;Liu,X.;Duan,T.;Chen, H.; Microchim. Acta, 2010, 171, 49-56.

${ }^{10}$ Mallah,M.H.;Shemirani,F.;Maragheh,M.G.; J. Radioanal. Nucl. Chem.,2008, 278, $97-$ 102.

${ }^{11}$ Sereshti,H.,Heravi,Y.E.;Samadi,S.; Talanta,2012, 97, 235-241.

${ }^{12}$ Fang,Z.L.; Flow-injection separation and preconcentration,VCH-Weinheim,1993.

${ }^{13}$ Wang,J.; Hansen,E.H.; J. Anal. At. Spectrom.,2002,17, 1284.1289.

${ }^{14}$ Sánchez,R.;Todolí,J.L.;Lienemann,C.P.;Mermet,J.M.;J.Anal.At.Spectrom.,2012,27, 937-945.

${ }^{15}$ Ardini,F.;Grotti,M.;Sánchez, R.;Todolí,J.L.; J.Anal.At.Spectrom.,2012,27,1400-1404.

${ }^{16}$ Maya,F.;Horstkotte,B.;Estela,J.M.;Cerdà,V.; TrAC-Trends Anal.Chem.,2014,59, 1-8. 
${ }^{17}$ Maya,F.;Horstkotte,B.;Estela,J.M.;Cerdà,V.; Anal. Bioanal. Chem.,2012,404, 909917.

${ }^{18}$ Růžička, J.;Marshall,G.D.;Anal. Chim. Acta,1990,237,329-343.

${ }^{19}$ Hansen,E.H.;Miró, M.;TrAC-Trends Anal.Chem.,2007,26,18-26.

${ }^{20}$ Horstkotte,B.;Suárez,R.;Solich,P.;Cerdà,V.; Anal. Chim. Acta,2013, 788, 52-60.

${ }^{21}$ Suárez,R.;Horstkotte,B.;Cerdà,V.; Talanta,2014,130, 555-560.

${ }^{22}$ Al-Saidi,H.M.;Emara,A.A.A.; J. Saudi Chem. Soc.,2014,18,745-761.

${ }^{23}$ Mitani,C.;Anthemidis,A.N.; Curr Anal. Chem.,2013, 9,250-278.

${ }^{24}$ Alexovič,M.;Horstkotte,B.,Solich, P.;Sabo,J.; Anal. Chim. Acta,2016,906, 22-40.

${ }^{25}$ Alexovič,M.;Horstkotte,B.,Solich, P.;Sabo,J.; Anal. Chim. Acta,2016,907, 18-30.

${ }^{26}$ Giordano,B.C.;Burgi,D.S.;Hart,S.J.;Terray,A.; Anal. Chim. Acta,2012,718, 11-24.

${ }^{27}$ Verboket,P.E.;Borovinskaya,O.;Meyer,N.;Günther,D.;Dittrich,P.S.;Anal. Chem.,2014, $86,6012-6018$.

${ }^{28}$ Miró,M.;Estela,J.M.;Cerdà,V.; Curr. Anal. Chem.,2005, 1,329-343.

${ }^{29}$ Anthemidis,A.N.;Miró,M.; Appl. Spectr. Rev.,2009, 44,140-167.

${ }^{30}$ Silvestre,C.I.C.;Santosa,J.L.M.; Lima,J.L.F.C.;Zagatto, E.A.G.;Anal.Chim.Acta, 2009, $652,54-65$.

${ }^{31}$ Giakisikli,G.G.;Miró, M.;Anthemidis,A.N.; Anal. Chem.,2013, 85, 8968-8972.

${ }^{32}$ Mitani, C.; Kotzamanidou, A.; Anthemidis, A.N.; J. Anal. At. Spectrom.,2014, 29, 1491-1498.

${ }^{33}$ Giakisikli,G.G.;Anthemidis,A.N.;Talanta, Talanta, 2017, 166, 364-368.

${ }^{34}$ Ramos,J.C.;Curtius,A.J.;Borges,D.L.G.; Appl. Spectr. Rev., 2012, 47,583-619.

${ }^{35}$ Ramos,J.C.;Borges,D.L.G.; J. Anal. At. Spectrom.,2014, 29,304-314.

${ }^{36}$ Dittert,I.M.;Vitali,L.;Chaves,E.S.;Maranhão,T.A.;Borges,D.L.G.,deFávere,V.T.;

Curtius, A.J.; Anal. Methods,2014, 6, 5584-5589. 
${ }^{37}$ Cocovi-Solberg,D.J.; Miró,M.; Anal. Bioanal. Chem.,2015, 407,6227-6233.

${ }^{38}$ Todolí,J.L.;Mermet,J.M.; J. Anal. At. Spectrom.,2003, 18,1185-1191.

1

2

3

4

5

6

7

10

11

12

13

14

15

16

17

18

19

20

21

22

23

24

25

26

27

28

29

30

31

32

33

34

35

36

37

38

39

40

41

42

43

44

45

46

47

48

49

50

51

52

53

54

55

56

57

58

59

60 


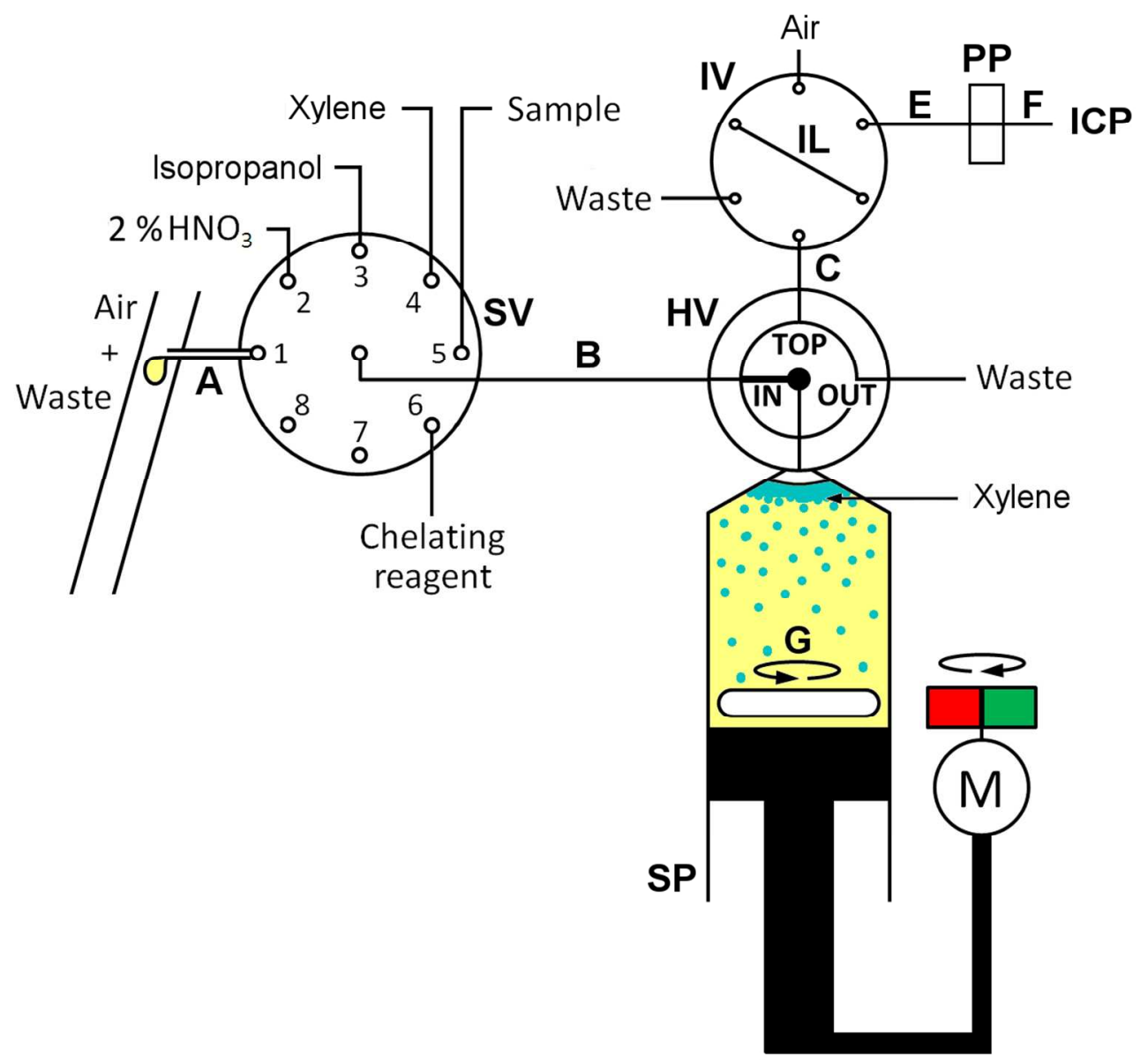

Figure 1

$457 \times 424 \mathrm{~mm}(72 \times 72$ DPI $)$ 


1
2
3
4
5
6
7
8
9
10
11
12
13
14
15
16
17
18
19
20
21
22
23
24
25
26
27
28
29
30
31
32
33
34
35
36
37
38
39
40
41
42
43
44
45
46
47
48
49
50
51
52
53
54
55
56
57
58
60

Figure 2

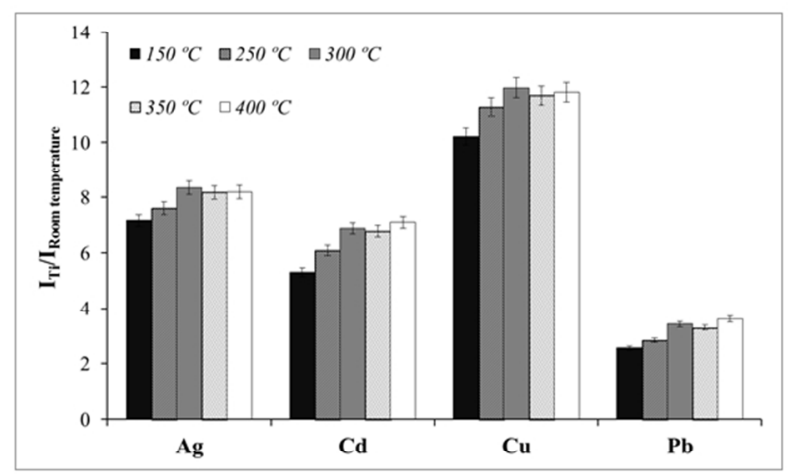

Figure 2

$254 \times 190 \mathrm{~mm}(96 \times 96 \mathrm{DPI})$ 